\title{
Realidades migratorias, un dilema para la acción comunitaria: el caso del barrio de Cuestas de Las Nieves, Canadá
}

\section{Ricardo Zúñiga B.}

\begin{abstract}
La acción comunitaria tiene una larga tradición en sociedades con poblaciones estables, con un encuadre de sociedad que es aceptado como meta posible por la gran mayoría de sus miembros. En contraposición, una sociedad de inmigración masiva obliga a buscar fundamentos para una acción comunitaria que combata las exclusiones con conciencia que ellas exigen mucho más que una incorporación a una estructura social. El desafío que presentan es el exigir una revisión radical de las premisas que hacían posible la exclusión por una revisión en profundidad de la estructura social que las albergaba. En una sociedad democrática, las inmigraciones masivas exigen un cambio real de la sociedad de acogida, que debe aceptar que incluirlas no es un gesto de altruismo, sino el reconocimiento de un derecho de nuevos ciudadanos a revisar las características de la sociedad de acogida que son incompatibles con una nueva sociedad inclusiva. Este trabajo estudia las formas que toma la acción comunitaria en un barrio de Montreal con altos índices de migración.
\end{abstract}

Palabras clave: Acción comunitaria / diversidad cultural / inmigración.

\section{Migration realities, a dilemma for community action service: the case of snow hill, canada}

\begin{abstract}
The community action service has a long tradition in societies with stable populations, with a society frame that is accepted as a feasible achievement by the great majority of its members. Otherwise, a society of massive immigration forces to look for foundations for a communitarian action that fights the exclusions considering that they demand much more that an incorporation to a social structure. The challenge that they posit is the demand of a radical revision of the premises that made the exclusion possible by means of an in-depth revision of the social structure that sheltered them. In a democratic society, massive immigrations demand a real change of the host society that must accept that including them is not an gesture of altruism, but the recognition of a right of new citizens to review the characteristics of the host society that are incompatible with a new inclusive society. This research work studies the forms that the community action takes in a district from Montreal with high migration rates.
\end{abstract}

Key words: Community action / cultural diversity / immigration

* Chileno-canadiense. Doctor en Psicología Social, Universidad de Harvard. Actualmente Profesor Asociado a la Escuela de Trabajo Social de la Universidad de Montreal. Correo electrónico: ricardozuniga@umontreal.ca 


\section{Antecedentes}

"Una sociedad moderna es aquella que acoge la diversidad y renuncia a la uniformidad. Por lo mismo, aspira propiamente no a la unidad, sino a instalar y compartir unos aceptables hábitos de convivencia entre sus miembros" (Squella, 2003:36).

Acoger la diversidad es un desafío para los países que aceptan ser tierra de acogida de inmigrantes, y que lo hacen en números que dejan toda ilusión o voluntad de uniformidad en la irrelevancia. La inmigración, así como la emigración, no son nunca procesos ordenados, previsibles y controlables. Los problemas sociales que viven los inmigrantes y la sociedad de acogida son frecuentemente sorpresas incómodas, que llevan necesariamente a la búsqueda de "adaptaciones razonables", las son y necesariamente debieran ser recíprocas. Es en este contexto, la acción comunitaria debe redefinir su misión.

En este trabajo mostramos el caso de un barrio de Montreal, en Quebec, Canadá. A partir de él se intenta ilustrar la realidad de una sociedad que ha optado por ser tierra de acogida, y plantear las bases fácticas de reflexión sobre los cambios de conciencia y de acción política a que se ve enfrentado el trabajo comunitario cuando el concepto mismo de proyecto colectivo debe aceptar que no podrá imponerse ni como ideal, ni como modo práctico de organización futura. La intención del artículo se sitúa en los debates actuales sobre la inmigración, que insisten en que la inclusión de inmigrantes es mucho más que un llamado a una cierta forma de caridad social, sino que toma la forma de un llamado humanitario a la inclusión. Los inmigrantes llegan con derechos humanos y luego ciudadanos que no podrán sino cuestionar el orden social que se había constituido sin ellos, y que deberá aceptar las modificaciones profundas que su inclusión verdadera tendrá derecho a exigir.

\section{Un barrio en Montreal}

No es fácil imaginarse un barrio formado por olas migratorias que lo caracterizan desde sus orígenes, producto de la acumulación sucesiva de escapados de crisis mundiales de todo orden. El barrio de Cuesta de las Nieves, en Montreal, es un ejemplo que puede permitir captar la complejidad del proceso social contemporáneo y los desafíos que confronta la acción comunitaria organizada. 
El Consejo de Desarrollo Comunitario, formado por 46 grupos voluntarios que trabajan con inmigrantes en el barrio, tiene plena conciencia de la historia de esta realidad social. Esta sociedad comienza francesa, pero se abre rápidamente a una variedad cultural, étnica y religiosa que es fiel reflejo de las crisis y persecuciones mundiales que llevan a emigraciones masivas. Si unos pocos franceses llegan huyendo la miseria desde 1698, ingleses, escoceses y americanos de la Nueva Inglaterra comienzan a llegar desde 1760, huyendo de los vientos revolucionarios de la reciente colonia disidente que amenaza a la corona británica, oponiéndose los sectores "leales", que prefieren huir a la colonia inglesa del Norte, es decir a Canadá, a los revolucionarios independentistas que formarán los Estados Unidos.

Desde 1810 los irlandeses comienzan a llegar, escapando a la opresión británica y a las hambrunas en su tierra, producto de la crisis de la papa. Desde 1835, los negros americanos encuentran la puerta de refugio que se les abre gracias a la ayuda de ciudadanos antiesclavistas que buscan librarlos de la esclavitud, llevándolos a casas secretas de refugio que los acerquen paulatinamente a Canadá. Desde 1889, rumanos, griegos y ucranianos se unen a esta búsqueda, y desde 1850 los alemanes, escandinavos, húngaros y polacos, seguidos por chinos e italianos desde 1880, y judíos a partir de 1890.

De estas inmigraciones, que pasan frecuentemente por Montreal como puerto de acogida hacia el resto del país, el barrio de Cuestas de las Nieves llega a contar en 1901, con 1557 habitantes.

La historia continúa, en los años '20 y '30, llega un nuevo influjo alemán, más checos y lituanos. Desde 1935, se agregan los portugueses, españoles y suizos. Desde 1950, se disminuyen las barreras que limitaban la llegada de chinos. Luego se reciben migrantes desde Pakistán, India y Sri Lanka. A un barrio que crece en forma exponencial, se agregarán los judíos sefarditas, algerinos, egipcios y marroquíes. Nuevas legislaciones facilitan la entrada de familias en programas de reunificación familiar.

En los años '70, América Latina contribuye con grupos significativos de personas que escapan de la persecución y miseria ligadas a sus realidades políticas, como el caso de América del Sur y a sus orígenes étnicos en América Central. Debido a una situación parecida, aumentan significativamente con los inmigrantes de Vietnam, Laos y Camboya, así como de Haití. 
Las actuales olas de inmigración provienen sobre todo de Rusia, China, Argentina y Colombia. Si tomamos estadísticas de 2007, el barrio recibió ese año migrantes desde:

\begin{tabular}{|l|c|}
\hline Origen & Número de migrantes \\
\hline Marruecos & 3.612 \\
\hline Francia & 3.467 \\
\hline Algeria & 3.414 \\
\hline Colombia & 2.542 \\
\hline China & 2.471 \\
\hline Rumania & 1.827 \\
\hline Líbano & 1.826 \\
\hline México & 1.304 \\
\hline Haití & 1.293 \\
\hline Irán & 1.110 \\
\hline Total anual & 22.866 \\
\hline
\end{tabular}

Fuente: QUÉBEC, Ministère de l'Immigration et Communautés culturelles, 2007

Si la inmigración ha apuntado a sectores juzgados más aptos para incorporarse a la sociedad de acogida en términos de competencias laborales y lingüísticas, ello no se ha limitado a un grupo de países juzgados con los mismos criterios. El resultado es una nueva sociedad con una variedad etnocultural que sólo se puede calificar de asombrosa.

No es raro que una escuela acoja a estudiantes provenientes de una cincuentena de países. Una profesora de educación inicial o educadora de párvulos, puede recibir niñas o niños que llegan hablando sólo inglés, español, árabe, vietnamita, farsi, ruso o suahili. Un servicio de urgencia hospitalaria puede recibir un accidentado frente al cual el primer problema es tratar de determinar a qué intérprete habrá que recurrir, para poder obtener la información mínima sobre las circunstancias de su accidente o estado de salud (cabe destacar que los hospitales tienen amplio acceso a servicios de traductores - además de un personal en que la variedad de lenguas de origen es conocida). Asimismo, el aeropuerto recibe decenas de personas que reclaman asilo político, que llegan sin documentos y sin posibilidades de comunicación o de indicar quiénes son las personas que pueden haber venido a acogerlos.

Cuando una escuela del barrio de Cuesta de las Nieves, tuvo la iniciativa de invitar a madres de comunidades inmigrantes a visitar la escuela para conversar con los niños y niñas en el período de des- 
canso entre clases y facilitar así un primer contacto, el catastro indicó que entre ellos hablaban 82 idiomas, todos mutuamente incomprensibles. Y con los idiomas aparecen las culturas y sus especificidades: examinar en el hospital una mujer en la ausencia de su marido; evaluar un posible caso de violencia familiar en una cultura patriarcal; servir una comida que sea aceptable en términos de restricciones religiosas; reglamentar en las escuelas el uso del carpan, (el puñal ritual de los Sikhs, que todo hombre adulto lleva como símbolo de su fe militante); qué hacer con el uso del chador o velo musulmán; cómo identificar en una situación de votación a una mujer de la que sólo se pueden ver los ojos en la única hendidura de la burqa negra que la cubre de pies a cabeza; las discusiones sobre si un crucifijo tiene lugar en una institución pública, etcétera, corresponden a temas esenciales de la identidad de quienes conforman una cultura determinada.

Debemos subrayar que hablamos de una inmigración de casi 23 mil personas al año, en un barrio de alrededor de 163 mil personas que comparten $20 \mathrm{Km}$. cuadrados, en una provincia autónoma que es menos de la mitad de Chile, que es parte de un país mayoritariamente inglés en lengua, cultura y relaciones políticas y comerciales 1. ¿Por qué mezclar marroquíes, colombianos, chinos, mejicanos, iraníes? La pregunta puede ser, más bien, ¿Por qué vivimos en un mundo tan diverso, en que las únicas constantes son la superabundancia de miseria, de persecución y de desigualdades y la voluntad apasionada de muchos que arriesgan peligros y sacrificios para defender su vida, sus convicciones y el futuro de su familia?

Estos párrafos no son anecdóticos, sino que corresponden a un punto de partida para afrontar la diversidad, porque la comunidad no puede confundir sus orígenes históricos con una defensa de su unidad, fusionándola con una legitimación de la uniformidad. La población de un país de inmigración no se puede explicar como

1 Formalmente, Canadá está ligado a la corona británica, y su autoridad suprema es la Reina de Inglaterra. Ella nombra un representante, el Gobernador General, que confirma como Primer Ministro al ganador de las elecciones. Toda sesión del Parlamento comienza con el Discurso del trono (que todos saben está redactado por el Primer Ministro), que es leído por el Gobernador General, mientras el Primer Ministro escucha respetuosamente. Los dos últimos Gobernadores Generales han sido mujeres, ambas inmigrantes (nacidas en China y en Haití, respectivamente). Cada provincia tiene un Gobernador provincial, también nombrado por la Reina como su representante directo. (El país tiene el suficiente respecto a la tradición británica como para no ver el humor de la situación). 
"gente pat'e perro". Ella refleja en mucho mayor grado una experiencia desgarradora de tener que cortar lazos ancestrales para salvar vida y dignidad humana, y para encontrar una promesa de futuro para sus familias.

Cuando se hallan en la "tierra de acogida", se encuentran entre extraños que los perciben como extraños, y extraños que ni siquiera dan pie a la creación de estereotipos defensivos, porque las generalizaciones son casi imposibles. ¿Cómo son los quebequenses?; y ¿a qué comunidad hay que "integrarse" -sin desarraigarse de la experiencia colectiva que los une a sus raíces, cuando se es ciudadano con múltiples pertenencias- acogido en el Quebec francés, proveniente de la India inglesa, con raíces y lengua Pashto, código ético Pashtuli y religión Sikh?; ¿Cuál es "su" comunidad?; ¿A qué queremos que renuncien para ser "canadienses normales", al menos "tolerables"?; ¿Qué amputaciones a su identidad se espera que acepten?

\section{El arraigo de los desarraigados recientes: La inmigración necesaria, acogida pero sólo parcialmente previsible}

El flujo migratorio sobrepasa las explicaciones individualistas de las motivaciones que la incitan, y sobrepasa los intentos de previsión y de planificación. Ni los inmigrantes encuentran completamente lo que buscaban, ni el país de acogida siente que los recién venidos son suficientemente "como nosotros" como para sacudirse la obligación fatigosa de acogerlos de modo comprensivo.

Tras los pedidos de asilo político pueden esconderse simples búsquedas de mejores condiciones de vida, o riesgos de la persecución global a grupos culturales o religiosos, razones que los tratados internacionales han excluido de la definición de una víctima de persecución política. Tras los esfuerzos aparentemente altruistas del país de acogida está la esperanza de una "integración", siempre mal definida, que se resume en un deseo inconfesable: que lleguen a ser como nosotros, tal como somos, tal como queremos seguir siendo, sin cuestionarnos ni aceptar que se nos critique. Puede que el candidato busque sólo beneficios económicos para él y su familia extensa, que el país de acogida sólo busque mano de obra calificada pero barata, dócil y humilde: ello sólo dificultará aún más decisiones siempre complejas. Tras los discursos autocomplacientes oficiales se encuentran realida- 
des que se prefieren ocultar: la calificación profesional de los inmigrantes no borra su alteridad (Bouchard y Taylor, 2008: 82-84)²

Las causas de tal discriminación son variadas, el mismo informe enumera las razones que pueden explicar tales obstáculos ${ }^{3}$. De ellas, es importante subrayar la jerarquización interna de la variedad de los distintos grupos acogidos. La gama de situaciones va desde la conciencia de sus derechos y el capital social de un ingeniero o médico marroquí, a la de una familia de campesinos turcos que sólo hablan Farsi y que no conocen ni la electricidad ni el transporte público y menos aún los trámites necesarios para establecer su condición refugiado, obtener sus documentos de identidad, inscribir sus hijos en la escuela. El Trabajo Social en este sentido cobra un rol relevante, ya que tales profesionales deben hacerse cargo de estas problemáticas con recursos siempre limitados.

El concepto de "inmigrante" sólo puede existir en una dicotomía entre "nosotros" y "ellos". Poquísimos serían los nuevos ciudadanos que se reconocerían como tales. Mucho más frecuentemente, quienes inmigran se auto representan como testigos de otros mundos, de otra cultura, en cierto modo modesto, como embajador de valores de los que está orgulloso y que quiere transmitir y compartir.

Muchos llegan al Canadá por caminos que los han aproximado por otros países, por ello han aprendido a vivir en varias culturas. El sen-

2 De los inmigrantes aceptados, el 60\% han sido elegido por sus competencias profesionales y lingüísticas. El resto está formado por el programa de reunificación familiar y por los reivindicadores de refugio político. El inmigrante es, así, alguien que no estaba destinado a ocupar los puestos mínimos de inserción. De los ciudadanos canadienses, el 14.7\% tiene títulos universitarios, el 27\% de los inmigrantes los posee. La inserción dista de ser fácil, sobre todo considerando esta realidad como una competencia de alto nivel. La tasa de cesantía de los inmigrantes con menos de 5 años de residencia es tres veces mayor que la local, y es aún el doble entre los que tienen entre 5 y 10 años de residencia. Ella oculta también que el empleo obtenido es muchas veces inferior al que corresponde a sus calificaciones (Bouchard y Taylor 2008: 82-84).

3 Entre estas razones se mencionan: "las reticencias a reconocer la formación y la experiencia obtenidas en el extranjero, un conocimiento insuficiente del idioma, las condiciones demasiado severas que rigen el acceso a oficios y profesiones, los perfiles de competencias que no corresponden a las necesidades de los empleadores, la concentración excesiva de los nuevos inmigrantes en la región de Montreal, el creciente carácter precario y generalizado del empleo y, por último, las prácticas discriminatorias que se ejercen especialmente con los grupos definidos racialmente (los inmigrantes provenientes de Asia, del Medio Oriente, de África y de América Latina) (Bouchard y Taylor 2008 : 85). 
tido identitario de pertenencias específicas hace siempre necesario situar cada grupo étnico y cultural y cada cohorte objeto reciente de inmigración, en su inserción histórica. Los problemas de los grupos recientes no son los de los grupos ya instalados (judíos Asquenazí, italianos, griegos), ni los de los grupos llegados intempestiva y masivamente debido a las persecuciones en sus países de origen (haitianos, vietnamitas, latinoamericanos y magrebinos)

Todos los problemas se agudizan con las discriminaciones sufridas por quienes el gobierno canadiense llama las "minorías visibles", que reúnen a haitianos, jamaicanos y africanos, y con las comunidades religiosas asociadas por la prensa con conflictos violentos, como Sikhs y musulmanes. La piel oscura y el velo como identidades "visibles" ponen a prueba los discursos abstractos sobre la igualdad de derechos. Cuando llega el momento de tomar decisiones políticamente comprometidas en la acción comunitaria, las comunidades étnicas y culturales se sitúan en posiciones diferentes en la política nacional y provincial. La diferencia tradicional entre comunidades étnicas o nacionales federalistas y provincialistas hace difícil buscar puntos de acuerdo común que puedan ignorar ambos contextos.

\section{Las múltiples identidades ciudadanas: construyendo una coexistencia}

Montreal es una puerta de entrada a la que acepta ser tierra de acogida. Las encuestas muestran una aceptación de $70 \%$ de las políticas de inmigración nacionales y provinciales, que prevén una recepción de más de 100 mil inmigrantes por año, que hacen de Canadá uno de los diez países que más inmigrantes aceptan en el mundo. En el caso de Québec, la provincia vive la ambigüedad de una relación siempre tensa entre los poderes provinciales (derecho a definirse como francófona, ministerios autónomos de salud y de educación, con sus propias normas de funcionamiento, control relativo de la inmigración, para preferir las demandas de habla francesa) y los poderes federales, que siempre tienen prioridad y que controlan presupuestos mucho más importantes, además de la política externa, que determina las consideraciones políticas que definen las prioridades de inmigración.

La importancia y la urgencia de encontrar soluciones, aunque sean puntuales, a las dificultades y tensiones ligadas a la inmigración han llevado al gobierno provincial a buscar una orientación fiable, que 
permita una mayor claridad consensual. Cuando el sistema político canadiense y quebequense confronta un dilema de esta naturaleza, recurre a una solución que legitime -y retarde- las decisiones políticas que deba tomar. Para ello, elige personalidades públicas que tengan el respeto de la población, y les da el mandato de organizar una Comisión de Estudio, que deberá hacer consultas populares en todas las regiones, y redactar un marco de análisis y de acción que pueda servir de guía al gobierno. En el caso de las tensiones interculturales nombró a Gerard Bouchard, un sociólogo de gran prestigio como intelectual, y a Charles Taylor, un filósofo que es probablemente el más vigente en Canadá, y especialista en los temas de la ciudadanía (2007) y de la construcción del sujeto en la modernidad (1998, 1989), y les dio el mandato de establecer una Comisión sobre las "Adaptaciones Razonables". Es decir, las concesiones recíprocas que deben hacer las diversas comunidades étnicas, culturales, nacionales y religiosas para poder "Vivir Juntos", o sea para "convivir".

El trabajo de la Comisión captó el interés de la población y su participación masiva y variada que consistió en: 13 estudios y 59 encuentros con expertos, 31 grupos de sondaje, 4 foros nacionales, 328 audiencias públicas con exposición y discusión de todas las memorias presentadas por grupos o ciudadanos; y 400 mil expresiones de opiniones en el sitio Internet de la Comisión, todo ello constituyó la base de datos. Las memorias presentadas representaron apasionadamente los grupos étnicos y culturales, los actores políticos y religiosos. El informe resultante (Bouchard y Taylor, 2008) es materia actual de debates políticos y de diálogos de grupos de interés.

\section{La inseguridad de una mayoría que es minoría}

El primer desafío de la Comisión ha sido el de identificar los rasgos de la sociedad de acogida. Quebec es parte de un Canadá mayoritariamente inglés primariamente como consecuencia de una derrota militar, que quebró definitivamente el lazo del territorio a la corona francesa ${ }^{4}$. El informe Bouchard-Taylor revela que los ciudadanos

4 Es importante comprender la experiencia que viven los quebequenses canadiensesfranceses. Miembros de una pequeña nación minoritaria en América, su cultura lleva la conciencia viva de las humillaciones, de las opresiones vividas y sobrepasadas, de las luchas por la supervivencia, de los combates que han debido enfrentar solos, sin poder apoyarse en aliados externos (Bouchard y Taylor 2008:98). 
sienten la obligación de defender los derechos adquiridos por la población de acogida ${ }^{5}$. Este punto de partida es un recuerdo de que toda búsqueda de convivencia deberá considerar que se vivirá un proceso que no será unidireccional -la integración incondicional-, sino interactivo, exigiendo cambios a las partes implicadas.

El prolongado trabajo de la Comisión sobre las Adaptaciones Razonables no cerró el debate. La crítica a la imposibilidad de desconectar los sistemas valóricos de los fundamentos ontológicos, religiosos o históricos que les atribuyen un valor absoluto, no concuerdan con un pensamiento respetuoso de la diversidad, que parece ser consecuencia sutil de un relativismo que acepta la diversidad, con el costo de reducirla al plano de las opiniones producto de subjetividades y de intereses de grupos de presión.

\section{La acción comunitaria entre la representación y la participación}

El financiamiento de los grupos comunitarios en Quebec está centrado en el apoyo gubernamental. Este apoyo se expresa en financiamientos por proyectos anuales, que deben responder a condiciones bastante estrictas en cuanto a sus metas y a su formato. No es raro, así, que la presentación de proyectos en términos de la planificación por objetivos imponga a los grupos la difícil tarea de desarrollar competencias de traducción, y de verter sus actividades reales en un tipo de formularios centrados en una lógica de insumo y producto ${ }^{6}$. Si la acción se desarrolla en un marco participativo, su financiamiento debe hablar en lenguaje administrativo. La tensión domina el campo de acción concreta como búsqueda de una síntesis pragmática ${ }^{7}$.

5 Laidentidad heredada del pasado canadiense francés es perfectamente legítima, y debe sobrevivir, pero ella ya no puede ocupar sola el espacio identitario quebequense. Tiene que articularse a las otras identidades presentes, en el espíritu del interculturalismo para prevenir la fragmentación (Bouchard y Taylor 2008:99-100)

6 Para un análisis crítico de la metodología dominante de formulación de proyectos y su impacto en la evaluación comunitaria, ver Laperrière y Zúñiga, (2007), y Zúñiga (2002).

7 Es práctica corriente el oponer la democracia representativa y la democracia participativa, tanto desde el punto de vista de la teoría como del de la práctica. Ellas son, en efecto, las dos grandes modalidades utilizadas en el seno de las democracias liberales para integrar las preferencias individuales y la consideración de sus aspiraciones. En el caso de la democracia representativa, la agregación se hace por medio del voto universal, sobre la base de programas electorales que defienden 
Esta tensión se refleja en el debate más en profundidad sobre las metas de una acción comunitaria que busca el establecer una relación más armónica entre la incorporación social, que es también integración a un modelo de sociedad preexistente, y una aproximación igualitaria de comunidades, que es una aceptación de la relativización de valores integradores.

La acción comunitaria tiene una larga historia de protección y defensa de minorías, y una tendencia natural a respetar la diversidad de la palabra. Sus formas de integración toleran una alta diversidad, y términos como los de "tablas de concertación", "foros" y "encuentros" buscan un diálogo que no genera estructuras centralizadas de control. El problema es la dificultad real al paso de certezas colectivas integradoras que reflejan colectivos de referencia (naciones, religiones) que son difícilmente materia de anexiones y de sincretismos. ¿Reemplazar la certeza integradora por un relativismo cultural, con la esperanza de que comunidades diferentes puedan coexistir sin homogenizarse en el modelo preexistente? Pocos se atreven a avanzar en el corolario filosófico que se deriva de la transición ${ }^{8}$. La crítica lleva a mostrar los problemas de la indefinición para la acción ${ }^{9}$

a priori posiciones diferentes y que permiten al cuerpo electoral hacer valer sus opciones, seleccionando el partido o la formación política que le conviene. La democracia participativa reposa, a la inversa, sobre la posibilidad de cada ciudadano de hacer valer sus preferencias sin imponerles marcos generales, y por la instauración de procedimientos e instituciones en cuyo seno es libre de expresar su voz, contribuyendo por este hecho mismo a la definición de opciones colectivas. Esta descripción de tipos ideales se encuentra raramente en la realidad de la vida política contemporánea (Hamel y Jouve, 2006:7-8).

8 La apertura al pluralismo y al valor equivalente de las diferentes reivindicaciones esquiva la cuestión central de la representación del bien común. Esta constatación no equivale a negar la apertura al pluralismo de la que acabamos de mostrar la necesidad, ni tampoco a asignar la acción a un proyecto ético-político único y monolítico. La crítica de la pragmática del compromiso busca subrayar el carácter paradojalmente apolítico de esta tendencia. | ... | La apertura a la diferencia en un espíritu de tolerancia constituye realmente un proyecto político para vivir juntos. | ... | En este enfoque, lo político queda reducido a su función de arbitraje del conflicto social, cuando constituye, y ello desde los albores de la modernidad, la instancia en el seno de la cual se elabora el proyecto de conjunto de la sociedad (Beauchemin 2004: 88-89)

9 La actitud ecuménica de Taylor es admirable, pero evita el que puede ser uno de los aspectos más importantes del aprieto espiritual moderno. Dado lo que ya la mayoría de nosotros acepta | .. |, no sólo es difícil entender qué significa ponerse en contacto con un orden transcendente, sino que además una conciencia que diferentes modos de entender ese orden, implican distintas afirmaciones de qué es el bien, y comprensiones radicalmente diferentes de cómo debemos conducir nuestras vidas. 
El punto de partida de un marco teórico para analizar la dinámica de la relación entre unidad y convivencia puede ser el de Squella $(2003)^{10}$, ya que permite buscar algunos elementos de comparación entre el caso quebequense, y su hipótesis respecto a Chile.

Para Squella, la sociedad chilena es más variada o plural que la imagen que ella tiene de sí misma, y esta variedad real, cuando es reconocida, es poco valorada positivamente (bajo pluralismo social), llevando a una tolerancia más pasiva que activa. "Tardamos mucho tiempo en aceptar la diversidad que de hecho se produce en los más diversos campos" (Squella 2003:40). La tolerancia activa está perjudicada por el discurso público dominante, ya que una aceptación activa de la diversidad sugiere la amenaza del relativismo moral que la sociedad no acepta explícitamente. Si bien la secularización es un proceso que ha venido cumpliéndose en la sociedad chilena, es más real en la base social que en las elites directivas (Squella, 2003:42).

Quebec presenta una imagen más de aceptación de la diversidad, más secular, desde el rechazo radical del clericalismo y de una religión que dictara decisiones políticas que data de los conflictos desde los años '60, al que se agrega su énfasis profundamente sentido y compartido del respeto de los Derechos Humanos, de la libertad individual como pilar fundamental de la sociedad, del rechazo violento de las participaciones de Canadá en guerras y misiones de intervención, y la valoración política de las misiones de paz con las Naciones Unidas.

¿Cómo vamos a incorporar esta dinámica, estos conflictos fundamentales en una sociedad pluralista? "La gente que tiene valores absolutos no puede ser integrada a una democracia", dijo una joven en las audiencias en Montreal, y la idea misma de un orden transcendente parece exigir alguna versión de valores permanentes. (Baird, 2008: 73).

10 Volviendo a la distinción entre unidad y convivencia, quizás si la primera se relacione con la idea tradicional de nación (que es un concepto cultural), mientras que la segunda lo haga con la idea de sociedad, un concepto de alcances propiamente políticos. Nación supone unidad cultural y en cierto modo moral de una comunidad. | ... | En cambio, sociedad alude a un pacto de convivencia entre quienes admiten tener diferencias y optan por la paz y la justicia -ambas relativas- que pueden proveer los vínculos asociativos e igualitarios, aunque no se inclinan por la instauración de una unidad cultural que uniforme las ideas religiosas, morales o de otro orden, puesto que, precisamente, lo que la sociedad persigue es mantener las diferencias (Squella 2003: 37). 


\section{Conclusión}

Más que señalar triunfos específicos, las políticas que favorecen la inmigración y la aceptación de refugiados políticos muestran los fundamentos de una tendencia a la aceptación de la diversidad y a la acogida mayoritaria de las aperturas internacionales activas. En el caso de Québec, el relativismo cultural, la tolerancia al espacio personal de decisiones y las adaptaciones razonables para evitar conflictos son valores profundamente anclados en la cultura popular, que no es proclive a crear conflictos y menos aún a resolverlos violentamente, donde las elites poco logran hacer para someterlos a normas abstractas.

El dilema está planteado para la acción comunitaria. ¿En qué grado su dinamismo está identificado con una estructura valórica que parece incuestionable -sean ellos la igualdad humana, el valor de la vida humana, la justicia distributiva, la castidad, la fidelidad, la honestidad- aún a riesgo de comprenderla en los términos con que se presentan en la sociedad de acogida?

Para todos estos valores, la posibilidad de encontrar una expresión absolutamente esencial, sin contaminaciones connotativas de historia, cultura, luchas fratricidas o intereses particulares, ha provisto de buena conciencia a misioneros, activistas, líderes carismáticos, profesionales del "cambio social", modernizadores, desarrollistas, lúcidos y funcionarios, permitiéndoles la conciencia tranquila que su causa era justa, y sus acciones justificadas, porque la forma local era la de su significación universal. Esta lógica de la integración provoca en la actualidad actitudes de rechazo a todo dogmatismo religioso o político, que hace de la apertura a la tolerancia una virtud indiscutible. La historia de los costos de la certeza en la acción humana planificada para asegurar la cristianización, la civilización, el progreso, el desarrollo y el cambio social son conocidos. ¿Cuál es la alternativa? Su búsqueda prosigue, sin respuestas que parezcan restablecer el equilibrio entre una ética de la tolerancia mutua y un relativismo cultural que haga difícil el hacer de ella una práctica social sin imposiciones.

En un país como Canadá, como en muchos otros, la acción comunitaria marcha sobre la fina línea que justifica la coexistencia de desigualdades violentas, con una esperanza de progreso colectivo. Como en la "teoría del goteo", lo intolerable como presente encuen- 
tra su justificación en un futuro en que la riqueza colectiva ofrecerá una mejoría a los sectores que viven lo que sólo es tolerable en la esperanza que sea una situación temporal en vías de ser superada. El discurso oficial asegura que los progresos en las medidas de tendencia central traerán necesariamente progresos en las medidas de dispersión, que el aumento del ingreso nacional promete el del ingreso individual de todos sus miembros. La teoría económica del "goteo" goza de un prestigio de perogrullo.

Cuando, como en el caso de la acción comunitaria en Québec, ésta se sostiene en financiamientos gubernamentales, su acción no puede sino aceptar el discurso del progreso colectivo, mientras continúa trabajando en un presente que lo cuestiona.

La inmigración pone sobre el tapete la realidad de las marginalidades y exclusiones, de un modo que hace de los inmigrantes un grupo que carga con el peso de ser ejemplo fácil de la necesidad de modificar las reglas de juego, que producen su miseria y que de ser modificadas, pueden disminuir también la de otros.

En el fondo, las comunidades étnicas viven en forma más acentuada las contradicciones que generan los problemas sociales que son los de la sociedad de acogida (cesantía, marginalizaciones, pobreza de sectores discriminados, recursos sociales que reflejan la estructura de desigualdades concretas). La esperanza es que, trabajando con minorías étnicas y culturales, se aumente también la visibilidad de los problemas sociales que son las consecuencias de las opciones sociales de la sociedad de acogida.

El caso de una comunidad política de más de cien mil ciudadanos en una provincia minoritaria de 7 millones de habla francesa, en un país de 33 millones de habitantes, lleva a una reflexión que va más allá del caso.

Una sociedad de acogida se debe de ir mas allá que de tratar la situación de los inmigrantes que ha acogido como una de "inclusión" dejando la impresión que esa sociedad se prepara a acoger -pero no se cuestiona sobre los presupuestos que le son cómodos. No porque somos democráticos e igualitarios la igualdad existe en los hechos, y menos aún como una igualdad respetuosa de diferencias, dispuesta a otorgarle sus plenos derechos de resistir las generalidades que las marginan. 
Etnias fundadoras, mujeres, religiones minoritarias, orientaciones sexuales e inmigrantes son categorías recientes, que exigen que el ser reconocidos en sus especificidades de vida, sea más que una invitación a fundirse con esa mayoría que no ve razones para cuestionarse y para cambiar, que olvida que son sus propias características las que han generado las discriminaciones y las exclusiones reales, tan difíciles de aceptar en el discurso autocomplaciente y que pretenden que son esas nuevas minorías con voz, quienes deben cambiar, para fundirse en la imagen cómodamente homogénea que permitía relegarlas a una marginalidad social.

La diversidad estaba con nosotros y rehusábamos confrontarla, y lo estará cada vez en mayor grado, y deberá ser reconocida como portadora de una posibilidad de desarrollar la conciencia crítica colectiva respecto a la distancia entre nuestros discursos universalistas y nuestras realidades que requieren un trabajo de honestidad práctica transformadora.

\section{Referencias biliográficas}

Beauchemin, J. (2004) La société des identités. Éthique et politique dans le monde contemporain. Québec : Outremont.

Baird, D. (2008) Charles Taylor's A Secular Age shows why religion remains a powerful force. The Walrus, April, 70-73.

Bouchard, G., Taylor, C. (2008)

Fonder l'avenir. Le temps de la conciliation. Commission de consultation sur les pratiques d'accomodation referées aux différences culturelles. Recuperado el 15 de Septiembre de 2008. de http://www.accomodements.qc.ca

Hamel, P., Jouve, B. (2006)

Un modèle québécois? Gouvernance et participation dans la gestion publique. Montréal: Presses de l'Université de Montréal.

Laperrière, H., Zúñiga, R. (2007)

Cuando la comunidad guía el cambio social: hacia una evaluación comunitaria alternativa. Ponencia presentada en VIII Congreso de Psicología Social de la Liberación, Teorías y Metodologías Críticas. Santiago de Chile, 10 de no- 
viembre de 2007. Disponible en el sitio Web del Congreso, http://sicoliberacion.blogspot.com/y en http://homepage.mac.com/ricardo.b.zuniga

Québec, Ministère de l'Immigration et Communautés culturelles (2008). Bulletin statistique trimestriel sur l'immigration permanente au Québec Direction de la recherche et de l'analyse prospective 2008-02-25.

Squella, A. (2003) ¿ ¿Necesitamos proteger una identidad o asumir y fomentar nuestra diversidad? En Montesino, Sonia, (Comp.) Revisitando Chile. Identidades, mitos e historias. Cuadernos Bicentenario, Publicaciones del Bicentenario, Presidencla de la República. Pp. 36-44.

Taylor, C. (2007) A Secular Age. Belknap Press, Harvard University. Cambridge, Mass.

Taylor, C. (1989) Sources of the self: The making of the modern identity. Cambridge, Mass.: Harvard. Traducción francesa: Les sources du moi. La formation de l'identité moderne. Québec, du Boréal (1998).

Zúñiga, R. (2002) La evaluación en la acción social. Autonomías y solidaridades (Manual de formación para un curso de investigación evaluativa en la Maestría en Trabajo Social, Escuela de Trabajo Social, Universidad de Montréal). Disponible en http://homepage.mac.com/ricardo.b.zuniga. 